\title{
ESTRESSE OXIDATIVO EM GIRASSOL (Helianthus annuus) INDICA Sinergismo para a Mistura dos Herbicidas MetribuZin e Clomazone $^{1}$
}

\author{
Oxidative Stress in Sunflower (Helianthus annuus) Indicates Synergism for the Metribuzin \\ Clomazone Combination
}

KRUSE, N.D. ${ }^{2}$, VIDAL, R.A. ${ }^{3}$, DALMAZ, C. ${ }^{4}$, TREZZI, M.M. ${ }^{5}$ e SIQUEIRA, I. ${ }^{6}$

\begin{abstract}
RESUMO - Determinações bioquímicas e físico-químicas são úteis para verificar o tipo de interação herbicida. Três experimentos foram conduzidos com dois herbicidas geradores de estresse oxidativo para demonstrar o possível sinergismo em sua associação. Plantas de girassol foram cultivadas em solução nutritiva até o estádio de dois pares de folhas, quando então os herbicidas foram aplicados. Os tratamentos consistiram de metribuzin a 0 e $0,28 \mu \mathrm{mol} \mathrm{L}^{-1}$ e clomazone a 0 e $80 \mu \mathrm{mol} \mathrm{L} \mathrm{L}^{-1}$, com quatro repetições, isolados e em mistura. No material coletado, três dias após a aplicação, determinou-se o malondialdeído (MDA), pelo método das substâncias reativas ao ácido tiobarbitúrico (TBARS). Em outro experimento, os herbicidas foram testados sobre 40 discos de $4 \mathrm{~mm}$ de folhas de girassol imersas em $5 \mathrm{~mL}$ de tampão MES-NaOH, em pH 6,5. Os tratamentos consistiram de metribuzin a 0 e $12 \mu \mathrm{mol} \mathrm{L}^{-1}$ e clomazone a 0 e $237 \mu \mathrm{mol} \mathrm{L}^{-1}$, com quatro repetições, isolados e em mistura. Os discos foliares tratados foram incubados por $24 \mathrm{~h}$ no escuro a $24{ }^{\circ} \mathrm{C} \mathrm{e}$ por 36 h sob luz, à mesma temperatura. A condutividade eletrolítica da solução foi então medida. Em relação ao metribuzin e clomazone aplicados isoladamente, a mistura dos dois herbicidas aumentou o equivalente MDA em 217 e 166\%, e a condutividade eletrolítica, em 37 e $41 \%$, respectivamente. Esses resultados demonstram, em nível bioquímico e físico-químico, a existência de sinergismo na mistura de metribuzin e clomazone, nas doses estudadas.
\end{abstract}

Palavras-chave: TBARS, condutividade eletrolítica, sinergismo, mistura de herbicidas.

\begin{abstract}
Biochemical and physical-chemical determinations can help verify the type of herbicide interaction. Three experiments were conducted with two oxidative stress generating herbicides to demonstrate possible synergism in their association. Sunflower plants were grown in nutrient solution up to the stage of two pairs of leaves, followed by herbicide application. Treatments consisted of

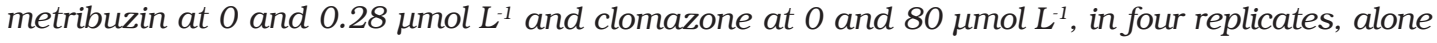
and in combination. In the material collected, three days after application, malondialdehyde content was determined by the TBARS method. In another experiment, the herbicides were tested over forty $4 \mathrm{~mm}$ sunflower leaf discs in $5 \mathrm{~mL}$ of $\mathrm{MES}-\mathrm{NaOH} \mathrm{pH} 6.5$ buffer. Treatments consisted of metribuzin at $O$ and $12 \mu \mathrm{mol} L^{-1}$ and clomazone at $O$ and $237 \mu \mathrm{mol} \mathrm{L}^{-1}$, in four replicates, alone and in combination. The treated leaf discs were dark-incubated for $24 \mathrm{~h}$ at $24{ }^{\circ} \mathrm{C}$ and light-incubated for $36 \mathrm{~h}$ at the same temperature. Electrolyte leakage of the solution was then measured. Compared to application of metribuzin and clomazone alone the two herbicide combination increased the MDA equivalent in $217 \%$ and $166 \%$, and electrolyte leakage in 37 and $41 \%$, respectively. These results demonstrate the existence of synergism in the metribuzin/clomazone combination at the studied rates, at a biochemical and physical-chemical level.
\end{abstract}

Keywords: TBARS, electrolyte leakage, synergism, herbicide combination.

\footnotetext{
Recebido para publicação em 4.8.2005 e na forma revisada em 5.5.2006.

2 Prof. do Dep. de Defesa Fitossanitária, Universidade Federal de Santa Maria - UFSM, 97110-900 Santa Maria-RS, <nkruse@terra.com.br>. ${ }^{3}$ Prof. do Dep. de Plantas de Lavoura, Universidade Federal do Rio Grande do Sul - UFRGS, <ribas.vidal@ufrgs.br>; ${ }^{4}$ Profa . do Dep. de Bioquímica da UFRGS, <cdalmaz@ufrgs.br>. ${ }^{5}$ Prof. da Universidade Tecnológica Federal do Paraná - UTFPR, 85503-390 Pato Branco-PR, <mtrezzi@ brturbo.com.br>. ${ }^{6}$ Prof ${ }^{a}$. do Centro Universitário UNIVATES, <ionara@ufrgs.br>.
} 


\section{INTRODUÇÃO}

A associação de herbicidas inibidores do fluxo de elétrons no fotossistema II (FS II) com herbicidas inibidores da síntese de carotenóides gera elevado estresse oxidativo, que culmina com a morte das plantas sensiveis (Devine et al., 1993). O estudo da interação existente nessa associação, se aditiva, sinérgica ou antagônica, é tarefa complexa e demanda abordagens em diferentes níveis. A intensidade dos efeitos do estresse oxidativo pode ser determinada na planta inteira, ou nos tecidos tratados e, mais especificamente, no nível celular. Para isso, é necessário avaliar variáveis que estejam diretamente relacionadas ao grau de estresse provocado. Assim, a estimativa do estresse oxidativo por esses indicadores, no nível celular, pode, ao lado de outras abordagens, fornecer elementos comprovadores do tipo de interação existente nesta associação (Devine et al., 1993; Green \& Streibig, 1993).

Os herbicidas inibidores do FS II, entre eles o metribuzin, exercem sua ação herbicida inicialmente pelo bloqueio do fluxo de elétrons do FS II. Esse bloqueio impede a transferência de energia da clorofila para o centro de reação $\mathrm{P}_{680}$, o que dá origem a uma clorofila altamente reativa, a clorofila tripleto $\left({ }^{3} \mathrm{Chl}\right)$. Esta clorofila reage com o oxigênio molecular, gerando espécies reativas de oxigênio (ERO). Todas essas moléculas altamente reativas irão reagir com os lipídios formadores das membranas, originando a peroxidação lipídica, que, além de formar novos radicais lipídicos, danificam irreversivelmente as membranas celulares (Hess, 2000; Fleck \& Vidal, 2001).

O estresse oxidativo gerado por esse mecanismo de ação herbicida é normalmente amenizado por ação das defesas naturais da planta ao estresse, destacando-se o papel dos carotenóides, os quais são capazes de reagir com as EROs, dissipando sua energia na forma de calor. Em condições normais, a ação dos carotenóides é suficiente para impedir o dano às membranas. Contudo, quando a planta é tratada com um herbicida como o metribuzin, a capacidade protetora dos carotenóides é ultrapassada e a planta sofre a peroxidação lipídica (Devine et al., 1993; Buchanan et al., 2000; Hess, 2000; Fleck \& Vidal, 2001).
Herbicidas como o clomazone têm seu mecanismo de ação centrado na inibição da rota de sintese dos carotenóides. Com a presença reduzida ou ausência de carotenóides, a planta fica sujeita à ação das ERO normalmente formadas, sofrendo os danos nas membranas da mesma forma descrita anteriormente. Por isso, hipotetiza-se que a associação de herbicidas inibidores do FS II, como o metribuzin, com herbicidas inibidores da síntese de carotenóides, como o clomazone, poderá apresentar ação sinérgica, pelo aumento do estresse oxidativo, de um lado, e pela redução das defesas naturais, de outro (Devine et al., 1993, Fleck \& Vidal, 2001; Kruse, 2001).

Tanto na utilização isolada do metribuzin como do clomazone, e em sua associação, ocorrerá o estresse oxidativo, desencadeando, então, a peroxidação de lipídios. Um dos metabólitos resultantes da peroxidação lipídica é o malondialdeído (MDA). Portanto, a sua determinação, ainda que de forma indireta, constitui-se em um indicador de avaliação do grau do estresse oxidativo formado pela ação isolada, ou mesmo conjunta, dos herbicidas considerados (Kenyon et al., 1985; Halliwell \& Gutteridge, 1989).

A conseqüência direta do dano às membranas celulares pela peroxidação lipídica é o extravasamento do conteúdo celular para o meio que estiver envolvendo os tecidos danificados, quando o dano for suficiente para tanto. Assim, a determinação do extravasamento eletrolítico em solução de incubação de tecidos vegetais tratados com os herbicidas, através da condutividade eletrolítica da solução, constitui-se em mais uma variável para avaliação do efeito dos herbicidas no nivel celular (Kenyon et al., 1985; Dayan et al., 1997; Li et al., 2000).

O presente trabalho foi conduzido com o objetivo de avaliar a existência de sinergismo na associação de herbicidas inibidores do FS II, como o metribuzin, com inibidores da sintese de carotenóides, como o clomazone, pela estimativa do estresse oxidativo, através dos niveis de MDA e do extravasamento eletrolítico.

\section{MATERIAL E MÉTODOS}

Três experimentos foram conduzidos para atingir os objetivos propostos. 


\section{Experimento com substâncias reativas do ácido tiobarbitúrico (TBARS)}

Os tratamentos testados neste experimento foram representados por aplicação dos herbicidas na solução nutritiva onde se cultivaram plântulas de girassol do híbrido DKB 11 . Foram testados metribuzin, nas doses de 0 e $0,28 \mu \mathrm{mol} \mathrm{L}^{-1}$, e clomazone, nas doses de $0 \mathrm{e}$ $80 \mu \mathrm{mol} \mathrm{L}{ }^{-1}$, aplicados isoladamente e em associação. As doses foram escolhidas atendendo ao critério de utilizar doses próximas daquela que provoca $50 \%$ do efeito total possível, denominada de $\mathrm{I}_{50}$. Normalmente esta dose encontra-se em região de resposta linear ao efeito do herbicida, por isso presta-se melhor para a comprovação de sinergismo (Tammes, 1964; Hamill \& Penner, 1973; Nash, 1981; Hatzios \& Penner, 1985; Seefeldt et al., 1995).

Para este experimento, sementes de girassol foram colocadas para germinação em meados de janeiro de 2001. Uma semana após, transplantaram-se três plântulas por vaso, com dimensões de $10 \mathrm{~cm}$ de diâmetro, $17 \mathrm{~cm}$ de altura e $1.200 \mathrm{~cm}^{3}$ de capacidade volumétrica. Os vasos de polietileno tereftalato (PET) foram mantidos revestidos com papel-alumínio. As plântulas foram fixadas em placa de isopor encaixada no vaso. A solução nutritiva utilizada foi preparada de acordo com o proposto por Hoagland \& Arnon, descrito em Hewitt (1966), com as seguintes concentrações: $\mathrm{Ca}\left(\mathrm{NO}_{3}\right)_{2} 4 \mathrm{H}_{2} \mathrm{O} 4 \mathrm{mmol} \mathrm{L}{ }^{-1} ; \mathrm{MgSO}_{4} \mathrm{H}_{2} \mathrm{O}$ $2 \mathrm{mmol} \mathrm{L}-1 ; \mathrm{KNO}_{3} 4 \mathrm{mmol} \mathrm{L}^{-1} ;\left(\mathrm{NH}_{4}\right)_{2} \mathrm{SO}_{4}$ $0,435 \mathrm{mmol} \mathrm{L}^{-1} ; \mathrm{KH}_{2} \mathrm{PO}_{4} \quad 0,5 \mu \mathrm{mol} \mathrm{L}^{-1}$; $\mathrm{MnSO}_{4} \mathrm{H}_{2} \mathrm{O} 2 \mu \mathrm{mol} \mathrm{L}{ }^{-1} ; \mathrm{CuSO}_{4} 5 \mathrm{H}_{2} \mathrm{O} 0,3 \mu \mathrm{mol} \mathrm{L}^{-1}$; $\mathrm{ZnSO}_{4} 7 \mathrm{H}_{2} \mathrm{O} 0,8 \mu$ moles L-1; $\mathrm{NaCl} 30 \mu \mathrm{mol} \mathrm{L}^{-1}$; $\mathrm{Na}_{2} \mathrm{MoO}_{4} 2 \mathrm{H}_{2} \mathrm{O} 0,1 \mu \mathrm{mol} \mathrm{L}-1 ; \mathrm{H}_{3} \mathrm{BO}_{3} 10 \mu \mathrm{mol} \mathrm{L}-1$ e FeEDTA $10 \mu \mathrm{mol} \mathrm{L}^{-1}$. Foram empregados $1.000 \mathrm{~mL}$ da solução por vaso, mantida com pH 6,5 e sob aeração constante. A cada três dias era completado o volume e verificado o $\mathrm{pH}$, sendo corrigido quando necessário com $\mathrm{NaOH} 1 \mathrm{~mol} \mathrm{~L}^{-1}$. O delineamento experimental foi completamente casualizado, com quatro repetições.

Os tratamentos herbicidas foram aplicados na solução nutritiva quando as plantas apresentavam o segundo par de folhas completamente expandidas. Preparou-se uma solução herbicida para cada dose testada, de forma que $1 \mathrm{~mL}$ desta solução, diluída no volume do vaso, resultasse na dose desejada. Para aplicação, retirava-se a placa de isopor com as plantas e adicionava-se a solução herbicida, agitando vigorosamente com auxílio de bastão de vidro. Nos três dias subseqüentes à aplicação, as plantas permaneceram em ambiente protegido (estufa plástica), com temperatura máxima média de $36{ }^{\circ} \mathrm{C}$ e mínima média de $20{ }^{\circ} \mathrm{C}$. A radiação teve duração de $11 \mathrm{~h} 18,11 \mathrm{~h} 30$ e $12 \mathrm{~h}$ (heliógrafo Fuess), respectivamente, para cada dia após a aplicação (DAA), com fluxo fotônico fotossintético máximo equivalente a $950 \mu \mathrm{mol} \mathrm{m} \mathrm{m}^{-2} \mathrm{~s}^{-1}$ (sensor quântico acoplado a porômetro Li-Cor 1600).

Quando do estabelecimento dos sintomas visuais nas folhas, ao final do terceiro dia, coletou-se o material para análise de MDA. Foram tomadas folhas do segundo par de cada planta presente nos vasos. Imediatamente após o secionamento da folha, foram retiradas as nervuras centrais, obtendo-se $0,5 \mathrm{~g}$ de tecido verde para a análise. Logo depois de pesadas, as folhas foram colocadas em tubos de reação (eppendorf) de 1,5 mL e mergulhadas em nitrogênio líquido, para imediato congelamento, sendo posteriormente armazenadas a $-80^{\circ} \mathrm{C}$ até o uso (Velikova et al., 2000).

Para estimativa do estresse oxidativo através da peroxidação lipídica, com a quantifição indireta de seu produto, o malondialdeído (MDA), pelo método das substâncias reativas ao ácido tiobarbitúrico (TBARS ou TBA) (Halliwell \& Gutteridge, 1989), seguiu-se o proposto por Heath \& Packer (1968), com algumas modificações (Du \& Bramlage, 1992; Hodges et al., 1999; Velikova et al., 2000; Fu \& Huang, 2001). O tecido vegetal congelado, imerso em nitrogênio líquido, foi triturado em almofariz e homogeneizado em $5 \mathrm{~mL}$ de ácido tricloro acético (TCA 0,1\% massa volume ${ }^{-1}$ ). O homogeneizado foi centrifugado a $10.000 \mathrm{~g}$ por 20 min em centrífuga refrigerada a $4^{\circ} \mathrm{C}$ (Sigma $3 \mathrm{~K} 30$ ), e $0,5 \mathrm{~mL}$ do sobrenadante foi adicionado a $1 \mathrm{~mL}$ de TCA 20\% + TBA 0,5\% (peso por volume). Após agitada, a mistura foi incubada em água a $90^{\circ} \mathrm{C}$ por $30 \mathrm{~min}$ e paralisada a reação ao final, por imersão dos tubos em banho de gelo. Foi feita então nova centrifugação a $10.000 \mathrm{~g}$ por $5 \mathrm{~min}$. Outros $0,5 \mathrm{~mL}$ do sobrenadante foram adicionados a $1 \mathrm{~mL}$ de TCA 20\%, sendo agitados, incubados, imersos em banho de gelo e centrifugados como já 
descrito. Durante esse processo, as amostras estiveram sempre refrigeradas em banho de gelo, excetuando-se a incubação. Foi então lida a absorbância (Spectronic ${ }^{\circledR}$ Genesis $^{\mathrm{TM}}$ II) a 532 e a $600 \mathrm{~nm}$, em que $532 \mathrm{~nm}$ representam a máxima absorção do complexo MDA-TBA e $600 \mathrm{~nm}$ a absorção de turbidez não-específica (Heath \& Packer, 1968; Du \& Bramlage, 1992; Hodges et al., 1999; Velikova et al., 2000; Fu \& Huang, 2001).

A quantidade do complexo MDA-TBA (equivalente $\mathrm{MDA}=$ eq. $\mathrm{MDA}$ ) foi calculada de três formas (a seguir). Na primeira forma de calcular eq. MDA (nmol por g de massa verde (MV) (Kwon et al., 1965; Halliwell \& Gutteridge, 1989) utilizou-se apenas a absorbância a $532 \mathrm{~nm}\left(\mathrm{~A}_{532+\mathrm{TBA}}\right)$, empregando a equação 1:

eq. $\mathrm{MDA}=60.000 \cdot\left\{\left(\mathrm{A}_{532+\mathrm{TBA}}\right) / 156\right\}$

A segunda forma de calcular eq. MDA (Heath \& Packer, 1968; Du \& Bramlage, 1992) utilizou absorbância de 532 e 600 nm ( ( $\left._{600+\mathrm{TBA}}\right)$, não descontando a absorbância das amostras sem TBA, empregando-se a equação 2.2:

$$
\text { eq. } \mathrm{MDA}=60.000 \cdot\left\{\left(\mathrm{A}_{532+\mathrm{TBA}}-\mathrm{A}_{600+\mathrm{TBA}}\right) / 156\right\}
$$

A terceira forma de calcular eq. MDA (Hodges et al., 1999) utilizou absorbância de 532 e 600 nm e descontou-se a absorbância das amostras sem TBA, empregando a equação 3:

$$
\text { eq. } \begin{aligned}
\mathrm{MDA} & =60.000 \cdot\left[\left\{\left(\mathrm{A}_{532+\mathrm{TBA}}-\mathrm{A}_{600+\mathrm{TBA}}\right)\right.\right. \\
& \left.\left.-\left(\mathrm{A}_{532-\mathrm{TBA}}-\mathrm{A}_{600-\mathrm{TBA}}\right)\right\} / 156\right]
\end{aligned}
$$

Os resultados obtidos de eq. MDA pelas equações $2.1,2.2$ e 2.3 foram submetidos à análise da variância, segundo o procedimento proposto por Flint et al. (1988), que oferece tratamento estatístico à fórmula de Limpel (Limpel et al., 1962; Devine et al., 1993), modificada por Colby (1967). O procedimento propõe a análise em esquema fatorial, com transformação dos dados para logaritmo decimal e a estimativa da interação $\mathrm{I}_{{ }_{\mathrm{ij}}}$ como forma de verificar a existência de sinergismo. A interação I- $_{i j}$ é estimada subtraindo-se do efeito dos herbicidas em associação $\mu_{\mathrm{ij}}$ os efeitos dos fatores isolados $\left(\mu_{\mathrm{i} 0}\right.$ e $\left.\mu_{\mathrm{oj}}\right)$ e somando-se o efeito dos níveis 0 dos dois fatores $\left(\mu_{00}\right)$, da seguinte forma:
$\mathrm{I}_{\mathrm{ij}}=\mu_{\mathrm{ij}}-\mu_{\mathrm{i} 0}-\mu_{\mathrm{oj}}+\mu_{\mathrm{oo}}$

(eq. 4)

Haverá a indicação de sinergismo se $\mathrm{I}_{\mathrm{ij}}>0$; antagonismo, se $\mathrm{I}_{\mathrm{ij}}<0$; e aditividade, se $\mathrm{I}_{\mathrm{ij}}=0$, todos com significância estatística, para variáveis que aumentem de magnitude com a ação herbicida, como as estudadas neste trabalho. É proposta uma rotina para o aplicativo computacional SAS ${ }^{\circledR}$, que executa a análise pelo modelo linear geral (GLM), testando a significância da interação diretamente como parâmetro do modelo (coeficiente de regressão) pelo teste $t$ (Flint et al., 1988).

Alternativamente a essa análise, foi realizada uma segunda análise da variância, para a variável eq. MDA calculada pela equação 3. Seguiu-se o esquema de classificação simples, com comparação entre as médias pelo teste Waller-Duncan (Riboldi, 1995a). Além dos quatro tratamentos testados (sem herbicida, metribuzin a $0,28 \mu \mathrm{mol} \mathrm{L}^{-1}$, clomazone a $80 \mu \mathrm{mol} \mathrm{L}^{-1}$ e metribuzin $0,28 \mu \mathrm{mol} \mathrm{L}^{-1}+$ clomazone $80 \mu \mathrm{mol} \mathrm{L}^{-1}$ ), foram calculados valores estimados pela fórmula de Limpel et al. (1962), expressa na equação 5 :

$$
\mathrm{E}=\mathrm{Y}_{1}+\mathrm{Y}_{2}\left(100-\mathrm{Y}_{1}\right) / 100
$$

em que E representa o valor esperado com a associação dos herbicidas e $\mathrm{Y}_{1} \mathrm{e}_{2}$ representam o resultado obtido pela aplicação isolada de cada herbicida, para cada repetição. Os valores obtidos dessa forma estimam o resultado esperado se a associação entre os herbicidas apresentar interação nula (aditividade). Se os resultados da associação forem superiores a esses, a interação será sinérgica, e antagônica, se forem inferiores (Limpel et al., 1962; Colby, 1967; Devine et al., 1993). Os valores esperados assim calculados foram comparados com os resultados do tratamento com a associação de metribuzin + clomazone, por comparação de dois tratamentos em amostras independentes quando $\mathrm{n}_{1}=\mathrm{n}_{2}$ (teste $t$ ) (Steel \& Torrie, 1980; Riboldi, 1993).

\section{Experimentos de condutividade eletrolitica}

Neste trabalho foi realizado um experimento preliminar para definir as doses a serem empregadas no experimento de associação dos herbicidas. Após definidas as doses necessárias para aumentar a condutividade eletrolítica 
em 50\% $\left(I_{50}\right)$, realizou-se o experimento de associação entre herbicidas. Em ambos os experimentos, os tratamentos testados foram aplicados em discos de folhas de girassol do híbrido DKB 11, coletadas quando as plantas estavam no estádio de dois a três pares de folhas verdadeiras.

\section{Definição de $I_{50}$}

Foram avaliadas curvas de resposta às doses para o metribuzin e clomazone, a fim de determinar a $\mathrm{I}_{50}$ para cada herbicida, nas condições do experimento em questão. A dose $\mathrm{I}_{50}$ é a que fornece a estimativa mais acurada possivel da sensibilidade da planta ao herbicida e, também, permite a comparação com outros experimentos (Seefeldt el al., 1995). Para avaliação da resposta às doses do herbicida metribuzin foram empregadas as concentrações de $0,5,10,20,40$ e $80 \mu \mathrm{mol} \mathrm{L}^{-1}$, e para o clomazone, de 0,50, 100, 200, 400 e $800 \mu \mathrm{mol} \mathrm{L}^{-1}$ (Seefeldt et al., 1995). As plantas de girassol que forneceram os discos foliares foram obtidas por semeadura, em meados de outubro, sobre bandejas de $25 \times 40 \times 10 \mathrm{~cm}$, contendo como substrato solo peneirado, cuja análise físico-química indicou $290 \mathrm{~g} \mathrm{~kg}^{-1}$ de argila, $19 \mathrm{~g} \mathrm{~kg}^{-1}$ de matéria orgânica, $25 \mathrm{mg} \mathrm{dm}^{-3}$ de $\mathrm{P}, 123 \mathrm{mg} \mathrm{dm}^{-3}$ de $\mathrm{K}$ e $\mathrm{pH}$ $\left(\mathrm{H}_{2} \mathrm{O}\right.$ :solo $\left.1: 1\right)$ de 6,0. As plantas foram mantidas em ambiente protegido (estufa plástica), com temperatura máxima média de $32{ }^{\circ} \mathrm{C}$, mínima média de $20{ }^{\circ} \mathrm{C}$, fotoperíodo médio de luz natural de 13 horas e fluxo fotônico fotossintético máximo de $950 \mu \mathrm{mol} \mathrm{m} \mathrm{m}^{-2} \mathrm{~s}^{-1}$ ao meio-dia. As plantas foram irrigadas sempre que necessário.

Duas semanas após a emergência das plântulas, folhas do segundo e do terceiro par foram secionadas das plantas e lavadas com a solução de incubação. Das folhas extraíramse 40 discos de $4 \mathrm{~mm}$ de diâmetro para cada repetição. Foram feitas três repetições para cada dose de herbicida testada. A solução de incubação continha água destilada com 1\% (massa volume $^{-1}$ ) de sacarose e $1 \mathrm{mmol} \mathrm{L}^{-1}$ do tampão (MES NaOH $\{2-(N$-morfolino)ácido etanosulfônico\}), pH 6,5. Os discos foram colocados em placas de Petri de $6 \mathrm{~cm}$ de diâmetro e $1,5 \mathrm{~cm}$ de altura, com $5 \mathrm{~mL}$ da solução de incubação. A esta solução foi adicionado 0,5 mL de solução contendo os herbicidas em diferentes concentrações, para atingir as doses estudadas (Kenyon et al., 1985; Dayan et al., 1997; Li et al., 2000).

Os discos foliares foram então incubados em câmara climatizada, por 24 h na ausência de luz e por 36 h sob fluxo fotônico fotossintético médio de $95 \mu \mathrm{mol} \mathrm{m} \mathrm{m}^{-2} \mathrm{~s}^{-1}$, sempre a $24 \pm 0,5^{\circ} \mathrm{C}$. Após os períodos de incubação, a solução sem os discos foi colocada em tubos e medida a condutividade eletrolítica por condutivímetro (Analion C-708) com eletrodo de platina e expressa em $\mu \mathrm{mho} \mathrm{cm}^{-1}$ (Kenyon et al., 1985; Dayan et al., 1997; Li et al., 2000).

Os resultados obtidos para cada herbicida foram ajustados pelo modelo log-logístico expresso na equação 6:

$\mathrm{y}=C+D-C / 1+\exp \left[b\left(\operatorname{Ln}(x)-\operatorname{Ln}\left(I_{50}\right)\right)\right]$ (eq. 6) em que $\mathrm{y}=$ variável resposta estimada; $C=$ valor de $y$ para a dose $0 ; D=$ valor máximo de $y ; \operatorname{Ln}(x)=$ logaritmo natural de cada dose; $\operatorname{Ln}\left(\mathrm{I}_{50}\right)=$ logaritmo natural da dose que provoca $50 \%$ do efeito máximo; e $b=$ parâmetro que indica a declividade da curva em torno de $\mathrm{I}_{50}$. Os resultados foram submetidos à análise de variância. Com o auxílio do aplicativo computacional SigmaPlot (SPSS Inc.), obteve-se a estimativa do parâmetro $\mathrm{I}_{50}$, que forneceu as doses a serem empregadas no experimento com a associação dos herbicidas (Green \& Streibig, 1993; Seefeldt et al., 1995).

\section{Experimento com condutividade eletrolitica para associação dos herbicidas}

Para o experimento de associação dos herbicidas, plantas de girassol do mesmo híbrido foram cultivadas da forma descrita anteriormente, com semeadura em meados de novembro. Neste experimento, as condições da estufa plástica foram de temperatura máxima média de $36{ }^{\circ} \mathrm{C}$ e mínima média de $20{ }^{\circ} \mathrm{C}$. A extração dos discos ocorreu duas semanas após a emergência das plântulas, seguindo o mesmo protocolo descrito para o experimento anterior.

Foram testados os herbicidas metribuzin, nas doses de 0 e $12 \mu \mathrm{mol} \mathrm{L}{ }^{-1}$, e clomazone, nas

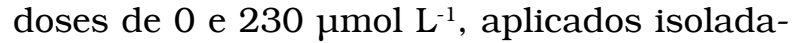
mente e em associação, com quatro repetições para cada tratamento, em delineamento completamente casualizado. Um quinto tratamento 
incluiu discos sem tratamento herbicida, que, após a incubação, foram imersos em banho de água a $95^{\circ} \mathrm{C}$, para provocar o máximo extravasamento eletrolítico possivel (Li et al., 2000).

Os resultados obtidos foram submetidos às mesmas análises estatísticas descritas no experimento com MDA. Na primeira forma de análise estatística aplicou-se o modelo proposto por Flint et al. (1988), para os valores originais de condutividade, expressos em $\mu \mathrm{mho}$ $\mathrm{cm}^{-1}$, com transformação para logaritmo decimal. A condutividade também foi expressa pelo índice de extravasamento eletrolítico relativo $\left(\mathrm{I}_{\mathrm{e}}\right)$, calculado utilizando-se a equação 7:

$I_{e}=100\left(R_{1}-R_{0}\left(1-R_{0}\right)\right.$

em que $R_{1}$ é a razão entre a condutividade de discos tratados e a máxima condutividade possível, obtida pelo tratamento de imersão em água a $95^{\circ} \mathrm{C} ; \mathrm{R}_{0}$, a razão entre a condutividade dos discos não-tratados e a máxima possível (Li et al., 2000). Na segunda forma de análise estatística fez-se a análise da variância em esquema de classificação simples, com os quatro tratamentos originais e o quinto tratamento com o banho-maria a $95^{\circ} \mathrm{C}$. As médias também foram comparadas pelo teste de Waller-Duncan (Riboldi, 1995a). Novamente foi aplicada a equação 5 sobre a variável $I_{e}$, e os valores esperados foram comparados com os resultados do tratamento com a associação de metribuzin + clomazone, por comparação de dois tratamentos em amostras independentes, quando $\mathrm{n}_{1}=\mathrm{n}_{2}$ (teste $t$ ) (Steel \& Torrie, 1980; Riboldi, 1993).

\section{RESULTADOS E DISCUSSÃO}

\section{Análise dos níveis de MDA}

O estresse oxidativo resultante da ação dos herbicidas metribuzin e clomazone provoca a peroxidação lipídica, danificando e destruindo as membranas celulares. Um dos compostos resultantes desta peroxidação é o MDA. Portanto, a intensidade da ação herbicida pode ser medida, no nível bioquímico, pela determinação dos níveis de eq. MDA no tecido tratado (Devine et al., 1993).

A estimativa do estresse oxidativo em folhas de girassol pela quantidade de eq. MDA, nas três formas diferentes de calcular o eq. MDA disponiveis na literatura, demonstra a necessidade de adotar métodos que subtraiam a absorbância de turbidez não-específica (Tabela 1). A equação 1 , que utiliza apenas a absorbância obtida no comprimento de onda de máxima absorção do aducto TBA-MDA, $532 \mathrm{~nm}$, é bastante empregada em tecidos de origem animal, para os quais o método TBA foi originalmente desenvolvido (Halliwell \& Gutteridge, 1989). Nesses tecidos, provavelmente, não ocorrem substâncias que possam

Tabela 1 - Equivalentes de MDA (eq. MDA) de folhas de girassol, calculados por três métodos distintos (equações 1, 2 e 3), em resposta à aplicação dos herbicidas metribuzin e clomazone isolados e em associação. UFRGS, Porto Alegre-RS, $2001 / 2002$

\begin{tabular}{|c|c|c|c|}
\hline \multirow{2}{*}{ Tratamento } & \multicolumn{3}{|c|}{ 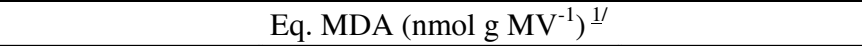 } \\
\hline & Equação 1 & Equação 2 & Equação 3 \\
\hline Tratamento sem herbicida & 17,4 & 11,5 & 11,2 \\
\hline Metribuzin $0,28 \mu \mathrm{mol} \mathrm{L}^{-1}$ & 13,9 & 10,5 & 9,9 \\
\hline Clomazone $80 \mu \mathrm{mol} \mathrm{L}^{-1}$ & 50,0 & 11,4 & 11,8 \\
\hline Metribuzin + clomazone & 42,2 & 33,7 & 31,4 \\
\hline Estimativa da interação ${ }^{2 !}$ & $-4,33$ & 23,27 & 20,95 \\
\hline Probabilidade $\left(t_{\text {calc. }}>t_{\text {tab. }}\right)$ & 0,70 & $<0,01$ & $<0,01$ \\
\hline $\mathrm{CV}(\%)$ & 6,13 & 11,01 & 3,06 \\
\hline
\end{tabular}

1 MV = massa verde; equação $1=\left\{\left(\mathrm{A}_{532+\mathrm{TBA}}\right) / 156\right\} 60.000$; equação $\left.2=\left\{\left(\mathrm{A}_{532+\mathrm{TBA}}-\mathrm{A}_{600+\mathrm{TBA}}\right)\right\} / 156\right\} 60.000$; equação $3=\left[\left\{\left(\mathrm{A}_{532+\mathrm{TBA}}-\mathrm{A}_{600+\mathrm{TBA}}\right)-\right.\right.$ $\left.\left.\left(\mathrm{A}_{532-\mathrm{TBA}}-\mathrm{A}_{600-\mathrm{TBA}}\right)\right\} / 156\right] 60.000$, em que $\mathrm{A}_{532+\mathrm{TBA}}=$ absorbância a $532 \mathrm{~nm}$ com TBA $\left(-\right.$ тBA $=$ sem TBA); $\mathrm{A}_{600}=$ absorbância a $600 \mathrm{~nm} ; 156=$ coeficiente de extinção molar do MDA em mmol cm$~_{-1} ; 60.000=$ fator de conversão.

$2 \mathrm{I}_{\mathrm{ij}}=\mu_{\mathrm{ij}}-\mu_{\mathrm{i} 0}-\mu_{0 \mathrm{j}}+\mu_{00}$, em que $\mathrm{I}_{\mathrm{ij}}=$ estimativa da interação segundo Flint et al. (1988); $\mu_{\mathrm{i}}=$ efeito dos herbicidas em associação; $\mu_{\mathrm{i} 0}$ e $\mu_{0 \mathrm{j}}=$ efeito dos herbicidas aplicados isoladamente; $\mu_{00}=$ efeito dos níveis 0 dos herbicidas. 
prejudicar a medida acurada de MDA. Já em tecidos vegetais esse método demonstra não ser adequado, pois a presença de outros compostos pode interferir na correta determinação dos níveis de MDA (Hodges et al., 1999).

A equação 1 superestimou os valores de eq. MDA em todos os tratamentos e, principalmente, no tratamento com clomazone, sendo até mesmo superior à associação dos herbicidas metribuzin e clomazone. Isso se refletiu na análise da interação existente na associação, pelo método proposto por Flint et al. (1988), e sugere interação antagônica (pelo valor negativo da estimativa da interação); contudo, como o teste $t$ não foi significativo, pela equação 1 , concluir-se-ia por interação nula. Quando a probabilidade da estimativa da interação for inferior a $\alpha(0,05)$, rejeita-se $\mathrm{H}_{0}$ (interação entre herbicidas nula). Caso a estimativa da interação seja positiva, confirmase, então, o sinergismo. Caso a estimativa da interação seja negativa, confirma-se o antagonismo (Flint et al., 1988).

Cabe ressaltar que a proposta inicial de Flint et al. (1988) foi de que há sinergismo quando a estimativa for menor do que zero e antagonismo quando for maior do que zero. Ocorre que os autores, no exemplo que apresentam, trabalham com a variável massa do caule, que decresce de magnitude com o tratamento herbicida, da mesma forma com que Colby (1967) exemplifica sua proposta. No presente trabalho, as variáveis estudadas (peroxidação de lipídios e extravasamento do conteúdo celular) aumentam de magnitude com o tratamento herbicida; portanto, é de se esperar sinergismo em estimativas de interação maiores do que zero. Por isso, quando for aplicada a proposta de Flint et al. (1988), é necessário considerar a natureza da variável estudada, em função do tratamento herbicida, adaptando o resultado de acordo com a variável em questão.

Os niveis de eq. MDA calculados pelas equações 2 e 3 (Tabela 1) apresentam estimativas da interação maiores do que zero, com probabilidade inferior a 0,05, confirmando, dessa forma, a existência de sinergismo na associação dos herbicidas e nas doses estudadas.

A obtenção de resultados opostos, exclusivamente pela forma de calcular os valores de eq. MDA (equaçãol versus equações 2 e 3 Tabela 1), demonstra a necessidade de se empregar a leitura da absorbância também a $600 \mathrm{~nm}$ na análise de tecido vegetal. Essa leitura permite retirar dos resultados a influência de outras substâncias presentes no tecido vegetal, que, reagindo com o TBA, absorvem luz em comprimento de onda próximos aos $532 \mathrm{~nm}$, mascarando os resultados. Há ainda autores que preconizam também a leitura a $440 \mathrm{~nm}$, a fim de retirar a influência de sacarose no resultado final, já que ela pode estar presente em tecidos como frutos, colmos e raízes e reagem com TBA (Du \& Bramlage, 1992).

As equações 2 e 3 para o cálculo do eq. MDA produziram resultados bastante semelhantes e possuem capacidade equivalente de demonstrar o sinergismo na associação dos herbicidas, nas doses empregadas. A diferença entre ambas está na condução paralela de subamostras com e sem TBA, para permitir a eliminação de interferência de compostos que, mesmo sem reagir com TBA, possam aumentar a absorbância nos comprimentos de onda utilizados. Pelos resultados equivalentes obtidos neste trabalho, verifica-se não haver necessidade de conduzir subamostras sem TBA, o que não garante que em outros tecidos ou espécies este procedimento não deva ser realizado (Hodges et al., 1999). De qualquer forma, adotar-se-ão os resultados da equação 3 como os definitivos para este trabalho.

A elevada significância $(\mathrm{P}<0,0001)$ obtida para a estimativa da interação entre herbicidas ser diferente de zero evidencia, em nivel bioquímico, o sinergismo na associação de metribuzin e clomazone, nas doses empregadas (Tabela 1). Os niveis de eq. MDA encontrados nas folhas de plantas tratadas com os herbicidas associados indicam a ocorrência de peroxidação lipídica em intensidade muito superior à encontrada nos tratamentos com os herbicidas aplicados de forma isolada. Convém ressaltar a acentuada superioridade dos níveis de eq. MDA do tratamento de metribuzin mais clomazone, não só em relação aos tratamentos com os herbicidas aplicados isoladamente, mas também no que se refere à estimativa obtida pela fórmula de Limpel et al. (1962) (equação 5) (Figura 1A). 

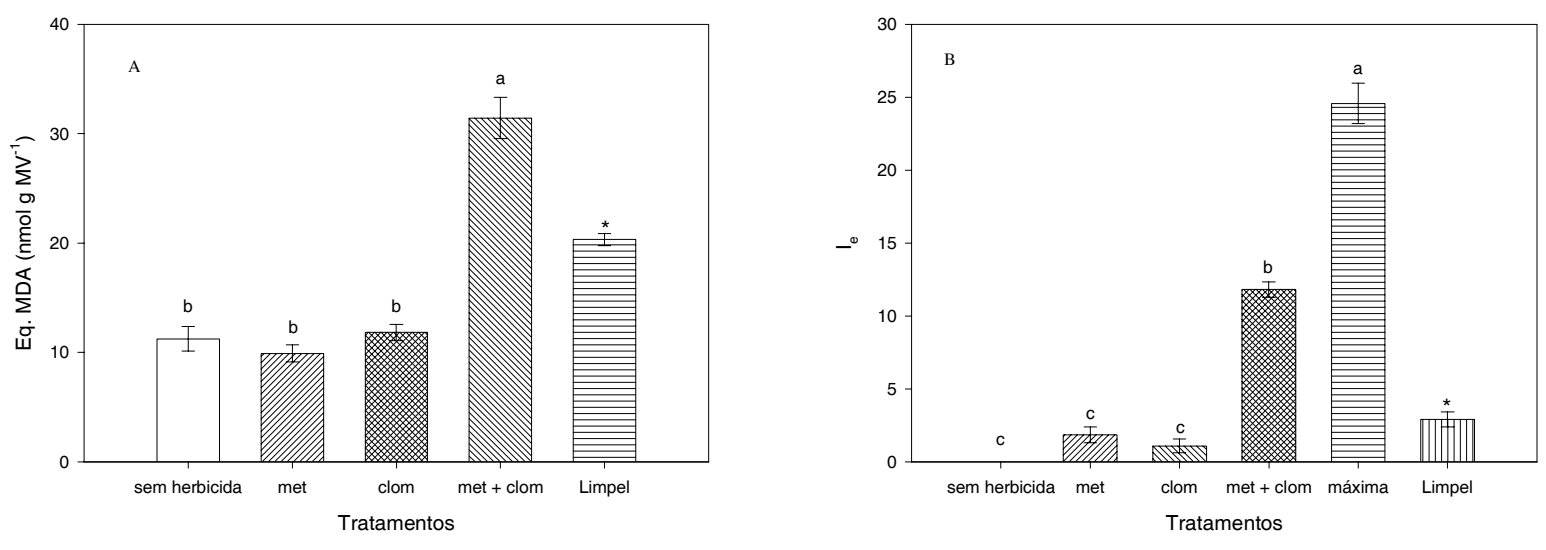

* Inferior a met + clom (teste $t, \mathrm{P}<0,01)$.

Figura 1 - Equivalentes de MDA (eq. MDA; massa verde = MV) (A) e índice de extravasamento eletrolítico (I $)(B)$ de folhas de girassol após tratamento com os herbicidas metribuzin (met) $\left(0,28 \mu \mathrm{mol} \mathrm{L}^{-1}\right)$ e clomazone (clom) $(80 \mu \mathrm{mol} \mathrm{L}-1)(\mathrm{A})$, met $12 \mu \mathrm{mol} \mathrm{L}{ }^{-1}$ e clom $237 \mu \mathrm{mol} \mathrm{L}-1$ (B), aplicados isolados e em associação (nas mesmas doses), e valores esperados pela fórmula de Limpel $(\mathrm{E}=\mathrm{X}+\mathrm{Y}(100-\mathrm{X}) / 100)$. Colunas abaixo de mesma letra não diferem a 5\% de significância (teste Waller-Duncan) e barras verticais representam o erro-padrão da média de cada tratamento. UFRGS, Porto Alegre-RS, 2001.

A inclusão de valores calculados pela equação 5 , comparados pelo teste $t$ com o tratamento metribuzin + clomazone, pretendeu fornecer uma alternativa ao modelo de análise proposto por Flint et al. (1988). Esse modelo foi justamente desenvolvido para preencher a lacuna deixada por Limpel et al. (1962) e Colby (1967), que não propuseram meio estatístico de comparação dos valores estimados com os realmente obtidos pela associação; todavia, o seu desenvolvimento inclui derivações matemáticas não tão facilmente disponiveis. Por isso, buscou-se produzir, alternativamente, uma análise de maior acessibilidade, também apresentando tratamento estatístico à fórmula de Limpel et al. (1962). Efetuou-se a comparação dos valores esperados com os realmente obtidos, aplicando-se a equação 5 para cada repetição dos tratamentos com metribuzin e clomazone aplicados isoladamente. A média assim calculada foi comparada com a média do tratamento com associação de metribuzin e clomazone, pela comparação de dois tratamentos em amostras independentes, quando $\mathrm{n}_{1}=\mathrm{n}_{2}$ (Steel \& Torrie, 1980; Riboldi, 1993).

Tanto a comparação entre as médias dos quatro tratamentos, pelo teste Waller-Duncan (Figura 1A), quanto a comparação entre as médias estimadas pela equação 5 demonstram o maior nível de peroxidação lipídica do tratamento com a associação dos herbicidas metribuzin e clomazone. Mais uma vez, de forma alternativa à anterior, fica evidenciada a existência de sinergismo na associação de metribuzin e clomazone, em nível da peroxidação lipídica, nas doses empregadas.

A magnitude dos níveis de eq. MDA encontrados, variando entre 11 e $31 \mathrm{nmol} \mathrm{g} \mathrm{MV}^{-1}$, está de acordo com a daqueles encontrados em outros trabalhos (Velikova et al., 2000; Prochazkova et al., 2001). Experimento que avaliou o estresse salino em girassol apresentou valores entre 10 e $40 \mathrm{nmol} \mathrm{g} \mathrm{\textrm {MV } ^ { - 1 } \mathrm { em }}$ raízes, colmos e calos das plantas (Vieira Santos et al., 2001). Trabalho sobre a senescência de folhas de espinafre relatou valores entre 10 e $40 \mathrm{nmol} \mathrm{g} \mathrm{MV}^{-1}$ (Hodges \& Forney, 2000).

A intensidade do estresse oxidativo provocado pela associação de metribuzin e clomazone fica ainda mais evidente quando se observa que os herbicidas aplicados isoladamente não produziram mais peroxidação lipídica do que a normalmente encontrada em plantas não tratadas (Figura 1A). Isso demonstra que as doses utilizadas foram inferiores às doses $I_{50}$ pretendidas, o que ressaltou o resultado obtido com a associação dos produtos, devido, provavelmente, à sua ação recíproca e potencializadora. 


\section{Análise do extravasamento eletrolítico}

Outra forma escolhida de analisar o efeito da associação dos herbicidas pelo estresse oxidativo provocado foi medir o extravasamento eletrolítico de discos foliares tratados com os herbicidas. O efeito final da ação herbicida, tanto do metribuzin quanto do clomazone, ainda que seu mecanismo de ação primário seja distinto, é o estresse oxidativo. O resultado desse estresse é a peroxidação das membranas celulares, que culmina com o extravasamento do conteúdo celular para o meio externo. A solução que receber este extravasamento terá sua condutividade eletrolítica aumentada, pela presença dos íons e compostos polares presentes no citosol. Portanto, quanto maior o estresse oxidativo, maior será a condutividade medida (Kenyon et al., 1985; Dayan et al., 1997; Li et al., 2000).

As curvas de resposta às doses obtidas no experimento preliminar de condutividade eletrolítica indicam que para metribuzin

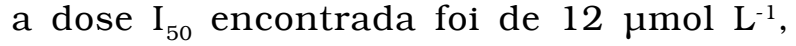
equivalendo a uma condutividade estimada de $825 \mu \mathrm{mho} \mathrm{cm}^{-1}$ (Figura 2A). O modelo log-logístico empregado ajustou adequadamente os resultados obtidos, produzindo coeficiente de determinação bastante elevado $\left(R^{2}=0,98\right)$, significando que grande parte da variabilidade da média de condutividade é explicada pelo modelo. Para o herbicida clomazone, encontrou-se a dose $\mathrm{I}_{50}$ de $237 \mu \mathrm{mol} \mathrm{L}^{-1}$

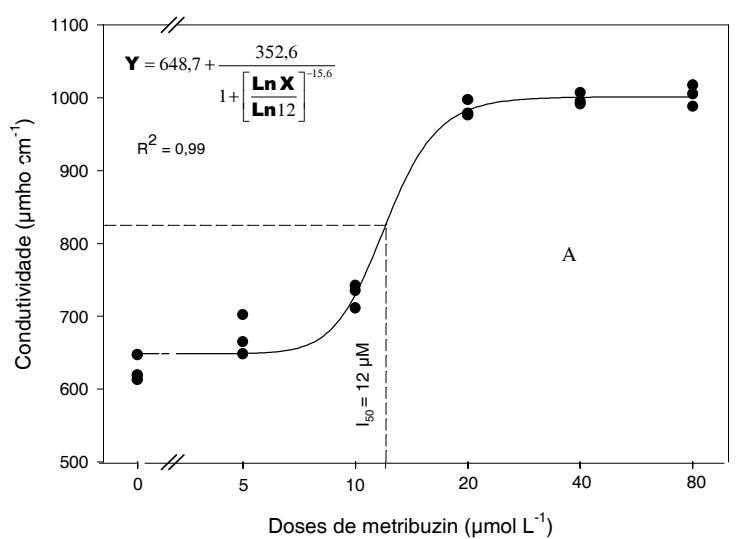

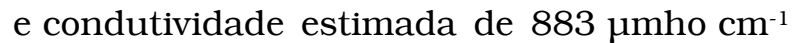
(Figura 2B). O ajuste do modelo log-logístico também foi adequado $\left(\mathrm{R}^{2}=0,99\right)$ para ajuste dos resultados obtidos (Riboldi, 1995b; Seefeldt et al., 1995).

Discos foliares de girassol, submetidos aos tratamentos com metribuzin e clomazone, isolados ou associados, nas doses $\mathrm{I}_{50}$, tiveram extravasamento do conteúdo celular, propiciando maior condutividade eletrolítica no tratamento com a associação dos herbicidas metribuzin e clomazone (Tabela 2). No método de análise estatística proposto por Flint et al. (1988), a estimativa da interação é maior do que zero, com alta significância estatística, o que indica ocorrer, nessas doses, o efeito de interação sinérgica entre os herbicidas metribuzin e clomazone. Trabalhos que utilizaram condutividade eletrolítica para avaliar o efeito de acifluorfen em pepino e sensibilidade de cultivares de soja ao sulfentrazone obtiveram niveis semelhantes de condutividade, com $300 \mu \mathrm{mho} \mathrm{cm}^{-1} \mathrm{em}$ pepino (apenas cinco horas de luz) e até $600 \mu \mathrm{mho} \mathrm{cm}^{-1}$ em soja (Kenyon et al., 1985; Dayan et al., 1997).

$\mathrm{O}$ índice de extravasamento eletrolítico relativo $\left(I_{e}\right)$ também apresenta estimativa da interação superior a zero, com elevada significância estatística $(\mathrm{P}<0,01)$ (Tabela 2$)$, confirmando o sinergismo na associação dos herbicidas metribuzin e clomazone, nas doses empregadas, em nível celular.

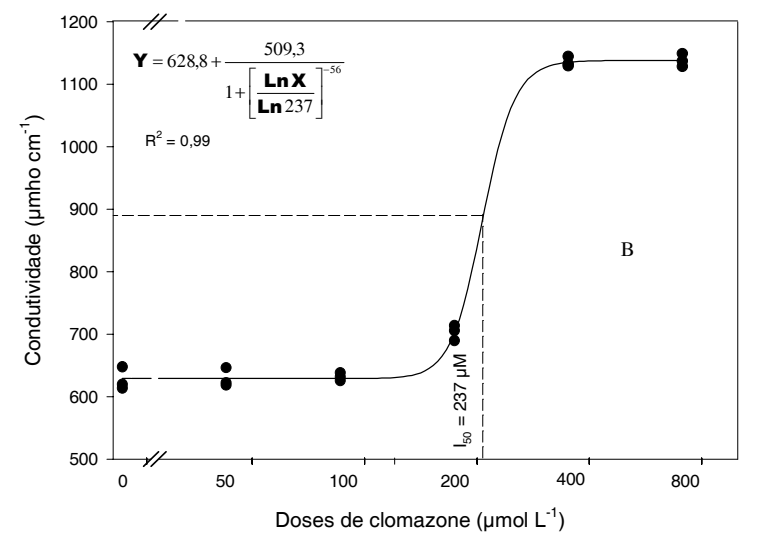

Figura 2 - Curva de resposta às doses da condutividade eletrolítica de discos foliares de girassol, sob doses crescentes de metribuzin (A) e clomazone (B). A linha contínua representa a curva ajustada pelo modelo log-logístico e os pontos representam os valores originais de cada repetição. A dose necessária para obter $50 \%$ de resposta $\left(\mathrm{I}_{50}\right)$, definida pelo modelo, está representada pela linha vertical tracejada. UFRGS, Porto Alegre-RS, 2001. 
Tabela 2 - Condutividade eletrolítica de discos foliares de girassol, em resposta à aplicação dos herbicidas metribuzin e clomazone isolados e em associação. UFRGS, Porto Alegre-RS, 2001

\begin{tabular}{|c|c|c|}
\hline \multirow{2}{*}{ Tratamento } & \multicolumn{2}{|c|}{ Condutividade eletrolítica } \\
\hline & $\left(\mu \mathrm{mho} \mathrm{cm}^{-1}\right)$ & $\mathrm{I}_{\mathrm{e}}{ }^{1 /}$ \\
\hline Tratamento sem herbicida & 653 & 0,0 \\
\hline Metribuzin $12 \mu \mathrm{mol} \mathrm{L}^{-1}$ & 701 & 1,8 \\
\hline Clomazone $237 \mu \mathrm{mol} \mathrm{L}^{-1}$ & 681 & 1,1 \\
\hline Metribuzin + clomazone & 962 & 11,8 \\
\hline Estimativa da interação ${ }^{2 /}$ & $0,12^{3 /}$ & 8,89 \\
\hline Probabilidade $\left(t_{\text {calc. }}>t_{\text {tab. }}\right)$ & $<0,01$ & $<0,01$ \\
\hline $\mathrm{CV}(\%)$ & 0,51 & 24,56 \\
\hline
\end{tabular}

1/ Índice de extravasamento eletrolítico relativo: $I_{e}=100\left(R_{1}-R_{0}\left(1-R_{0}\right)\right.$, em que $R_{1}$ é a razão entre a condutividade de discos tratados e a máxima

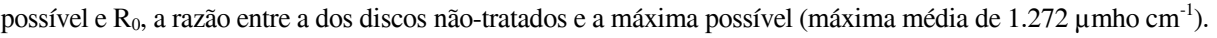

$\stackrel{2}{\prime} \mathrm{I}_{\mathrm{ij}}=\mu_{\mathrm{ij}}-\mu_{\mathrm{i} 0}-\mu_{0 \mathrm{j}}+\mu_{00}$, em que $\mathrm{I}_{\mathrm{ij}}=$ estimativa da interação segundo Flint et al. (1988); $\mu_{\mathrm{i}}=$ efeito dos herbicidas em associação; $\mu_{\mathrm{i} 0}$ e $\mu_{0 \mathrm{j}}=$ efeito dos herbicidas aplicados isoladamente; $\mu_{00}=$ efeito dos níveis 0 dos herbicidas. Se $\mathrm{I}_{\mathrm{ij}}>0 \Rightarrow$ interação sinérgica; se $\mathrm{I}_{\mathrm{ij}}=0 \Rightarrow$ interação aditiva; e se $\mathrm{I}_{\mathrm{ij}}<0 \Rightarrow$ interação antagônica, todos quando a probabilidade de $t_{\text {calc. }}>t_{\text {tab }}<0,05$.

3/ Valores transformados para logaritmo decimal.

A expressão dos dados pelo $I_{e}$ tem por finalidade apresentar os resultados extraindose dos tratamentos os níveis observados na solução sem tratamento herbicida e em função da máxima condutividade produzida pelos discos foliares (em banho-maria com água fervente). Neste experimento a condutividade máxima média (quatro repetições) foi de $1.272 \mu \mathrm{mho} \mathrm{cm}^{-1}$. Essa transformação compensa as diferenças potenciais entre tecidos, permitindo a comparação com outros trabalhos (Huang et al., 1997; Li et al., 2000).

Em trabalho que objetivou analisar a sensibilidade de cultivares de soja ao herbicida sulfentrazone, foram obtidos $I_{e}$ que variaram de 0,8 para cultivares tolerantes a 8,8 para cultivares sensiveis (Li et al., 2000). Esses resultados corroboram o emprego desta metodologia como forma de avaliação do efeito herbicida em nível celular.

O procedimento adotado para a variável eq. MDA, de comparação dos valores estimados pela equação 5 com os resultados do tratamento com a associação metribuzin + clomazone, também foi adotado para a variável $\mathrm{I}_{\mathrm{e}}$. Incluiu-se também o valor máximo de condutividade, obtido pela imersão da solução em banho-maria de água a $95^{\circ} \mathrm{C}$. A comparação entre as médias dos tratamentos pelo teste Waller-Duncan demonstra claramente o maior extravasamento eletrolítico provocado pela associação dos herbicidas, tanto em relação ao provocado pelos herbicidas isoladamente como pelo efeito esperado, calculado pela fórmula de Limpel et al. (1962) (Figura 1B) e comparado com a média do tratamento de associação pelo teste $t$.

Verifica-se que mesmo a associação dos herbicidas não provocou o máximo extravasamento possivel (Figura 1B). Especula-se que poderia ter-se deixado transcorrer mais tempo de incubação no período luminoso, ou com maior intensidade de luz, para se acentuar o extravasamento do conteúdo celular. Em trabalho em intensidade de luz semelhante à empregada no presente trabalho, em que foram testados vários tempos de incubação, o período de 36 horas permitiu o máximo extravasamento, mas representou apenas $73 \%$ do obtido com o tratamento de banho-maria (Li et al., 2000). Vale considerar que o tratamento com o banho-maria serve como referência para poder calcular o $\mathrm{I}_{\mathrm{e}} \mathrm{e}$ não necessariamente deve ser atingido pelos tratamentos herbicidas (Huang et al., 1997; Li et al., 2000).

Já os tratamentos com os herbicidas aplicados isoladamente equivaleram-se entre si e com o tratamento sem herbicida. Esse resultado, de certa forma, se deve à forma de calcular o $\mathrm{I}_{\mathrm{e}}$, que toma o máximo extravasamento como referência para expressão dos demais, o que reduz ainda mais as diferenças de baixa magnitude. 
A análise conjunta dos resultados de eq. MDA e condutividade eletrolítica, como forma de estimar o estresse oxidativo provocado pelos herbicidas metribuzin e clomazone, aplicados isolados e em associação, permite detectar a existência de interação sinérgica na ação conjunta desses herbicidas, pelo menos entre os dois conjuntos de doses empregados em cada um dos trabalhos. Os resultados de eq. MDA asseguram a estimativa do estresse oxidativo por um parâmetro bioquímico, já que o MDA é o composto resultante da peroxidação lipídica, gerada pelo estresse. Em complemento a estes, os resultados de condutividade eletrolítica estimam o estresse através de um parâmetro físico-químico, conseqüência do primeiro, uma vez que o rompimento das membranas causa o extravasamento eletrolítico. Portanto, são duas formas de medir a ação dos herbicidas na sua capacidade de destruir as membranas do vegetal e atingir seu objetivo. Ambas as variáveis demonstraram que a ação de um herbicida é facilitada pela do outro, confirmando a hipótese de que a redução da capacidade protetora da planta pelo herbicida inibidor da síntese de carotenóide facilita a ação geradora de estresse oxidativo pelo herbicida inibidor do fluxo de elétrons do FS II.

O estresse oxidativo em plântulas de girassol, estimado pelos níveis do metabólito resultante da peroxidação lipídica e pela ruptura das membranas celulares, através do extravasamento eletrolítico, comprova a existência de sinergismo na associação dos herbicidas metribuzin e clomazone.

\section{LITERATURA CITADA}

BUCHANAN, B. B.; GRUISSEM, W.; RUSSELL, L. J. Biochemistry and molecular biology of plants. Rockville: American Society of Plant Physiologists, 2001. 1367 p. Parte 1: Compartments.

COLBY, S. R. Calculating synergistic and antagonistic responses of herbicide combinations. Weeds, v. 15, n. 1, p. 20-22, 1967.

DAYAN, F. E. et al. Soybean (Glycine max) cultivar differences in response to sulfentrazone. Weed Sci., v. 45, n. 6, p. 634-641, 1997.

DEVINE, M.; DUKE, S. O.; FEDTKE, C. Physiology of herbicide action. Englewood Cliffs: PTR Prentice Hall, 1993. $441 \mathrm{p}$.
DU, Z.; BRAMLAGE, W. J. Modified thiobarbituric acid assay for measuring lipid oxidation in sugar-rich plant tissue extracts. J. Agric. Food Chem., v. 40, n. 9, p. 1566-1570, 1992.

FLECK, N. G.; VIDAL, R. A. Herbicidas inibidores do fotossistema 2. In: VIDAL, R. A.; MEROTTO Jr., A. (Eds.). Herbicidologia. Porto Alegre: 2001. p. 100-112.

FLINT, J. L.; CORNELIUS, P.L.; BARRETT, M. Analyzing herbicide interactions: a statistical treatment of Colby's method. Weed Technol., v. 2, n. 3, p. 304-309, 1988.

FU, J.; HUANG, B. Involvement of antioxidants and lipid peroxidation in the adaptation of two cool-season grasses to localized drought stress. Environ. Exp. Bot., v. 45, n. 2, p. 105-114, 2001.

GREEN, J. M.; STREIBIG, J. C. Herbicide mixtures. In: STREIBIG, J. C.; KUDSK, P. Herbicide bioassays. Florida: CRC Press, 1993. p. 117-135.

HALLIWELL, B.; GUTTERIDGE, J. M. C. Free radicals in biology and medicine. Oxford: Oxford University Press, 1989. $543 \mathrm{p}$.

HAMILL, A. S.; PENNER, D. Interaction of alachlor and carbofuran. Weed Sci., v. 21, n. 4, p. 330-335, 1973.

HATZIOS, K. K.; PENNER, D. Interactions of herbicides with other agrochemicals in higher plants. Rev. Weed Sci., v. 1, p. 1-63, 1985.

HEATH, R. L.; PACKER, L. Photoperoxidation in isolated chloroplast I. Kinetics and stoichiometry of fatty acid peroxidation. Arch. Biochem. Biophys., v. 125, n. 2, p. 189-198, 1968.

HESS, F. D. Light-dependent herbicides: an overview. Weed Sci., v. 48, n. 2, p. 160-170, 2000.

HEWITT, E. J. Sand and water culture methods used in the study of plant nutrition. 2.ed. East Maling: Commonwealth Agricultural Bureau, 1966. 159 p.

HODGES, D. M. et al. Improving the thiobarbituric acidreactive-substances assay for estimating lipid peroxidation in plant tissues containing anthocyanin and other interfering compounds. Planta, v. 207, n. 4, p. 604-611, 1999.

HODGES, D. M.; FORNEY, C. F. The effects of ethylene, depressed oxygen and elevated carbon dioxide on antioxidant profiles of senescing spinach leaves. J. Exp. Bot., v. 51, n. 344, p. 645-655, 2000.

HUANG, B. R.; DUNCAN, R. R.; CARROW, R. N. Drought-resistance mechanisms of seven warm-season turfgrasses under surface soil drying: II. root aspects. Crop Sci., v.37, n.6, p.1863-1869, 1997.

Planta Daninha, Viçosa-MG, v. 24, n. 2, p. 379-390, 2006 
KENYON, W. H.; DUKE, S. O.; VAUGHN, K. C. Sequence of effects of acifluorfen on physiological and ultrastructural parameters in cucumber cotyledon discs. Pest. Biochem. Physiol., v. 24, n. 2, p. 240-250, 1985.

KRUSE, N. D. Inibidores da síntese de carotenóides. In: VIDAL, R. A.; MEROTTO Jr., A. (Eds.) Herbicidologia. Porto Alegre: 2001. p. 113-122.

KWON, T.; MENZEL, D. B.; OLCOTT, H. S. Reactivity of malonaldehyde with food constituents. J. Food Sci., v. 30, n. 1, p. 808-813, 1965.

LI, Z. et al. Using electrolyte leakage to detect soybean (Glycine max) cultivars sensitive to sulfentrazone. Weed Technol., v. 14, n. 4, p. 699-704, 2000.

LIMPEL, L. E.; SCHULDT, P. H.; LAMONT, D. Weed control by dimethyl tetrachloroterephthalate alone and in certain combinations. Proc. North. Weed Control Conf., v. 16, p. $48-53,1962$.

NASH, R. G. Phytotoxic interaction studies - techniques for evaluation and presentation of results. Weed Sci., v. 29, n. 2 , p. $147-155,1981$.

PROCHAZKOVA, D. et al. Oxidative stress and antioxidant activity as the basis of senescence in maize leaves. Plant Sci., v. 161, n. 4, p. 765-771, 2001.

RIBOLDI, J. Cadernos de matemática e estatística: elementos básicos de estatística. Porto Alegre: Universidade Federal do Rio Grande do Sul, 1993. 61 p. (Instituto de Matemática - UFRGS, série B, 14 ).
RIBOLDI, J. Cadernos de matemática e estatística: análise de variância. Porto Alegre: Universidade Federal do Rio Grande do Sul, 1995a. 105 p. (Instituto de Matemática UFRGS, série B, 27).

RIBOLDI, J. Cadernos de matemática e estatística: análise de regressão e correlação. Porto Alegre: Universidade Federal do Rio Grande do Sul, 1995b. 75 p. (Instituto de Matemática - UFRGS, série B, 30).

SEEFELDT, S. S.; JENSEN, J. E.; FUERST, E. P. Loglogistic analysis of herbicide dose-response relationships. Weed Technol., v. 9, n. 2, p. 218-225, 1995.

STEEL, R. G. D.; TORRIE, J. H. Principles and procedures of statistics: a biometrical approach. 2.ed. New York: McGraw-Hill Book Company, 1980. 633 p.

TAMMES, P. M. L. Isoboles, a graphic representation of synergism in pesticides. Nether. J. Plant Pathol., v. 70, n. 2, p. 73-80, 1964.

VELIKOVA. V.; IORDANOV, I.; EDREVA, A. Oxidative stress and some antioxidant systems in acid rain-treated bean plants: protective role of exogenous polyamines. Plant Sci., v. 151, n. 1, p. 59-66, 2000.

VIEIRA SANTOS, C. L. et al. In situ and in vitro senescence induced by KCL stress: nutritional imbalance, lipid peroxidation and antioxidant metabolism. J. Exp. Bot., v. 52, n. 355, p. 351-360, 2001. 